\title{
The Maternal to Zygotic Transition in Animals and Plants
}

\author{
C. Baroux,${ }^{* \dagger}$ D. Autran,$\stackrel{+}{\dagger}$ C.S. Gillmor,${ }^{\S}$ D. Grimanelli, $\stackrel{+}{\dagger}$ And U. Grossniklaus* \\ *Institute of Plant Biology \& Zürich-Basel Plant Science Center, University of Zürich, CH-8008 Zürich, \\ Switzerland; 'IRD, Institut de Recherche pour le Développement, UMR 5096, BP 56501, 34394 Montpellier \\ Cedex 5, France; ${ }^{\S}$ Department of Biology, University of Pennsylvania, Philadelphia, Pennsylvania 19104
}

\begin{abstract}
In the animal kingdom, maternal control of early development is a common feature. The onset of zygotic control over early development, defined as the maternal to zygotic transition (MZT), follows fertilization with a delay of a variable number of cell divisions, depending on the species. The MZT has been well defined in animals, but investigations remain in their infancy in plants. Recent evidence suggests, however, that in plants as in animals, the MZT also occurs several division cycles after fertilization. The likely convergent evolution of the MZT in the animal and plant kingdoms is fascinating and raises major questions regarding its biological significance, particularly with regard to its importance in genome reprogramming and the acquisition of totipotency by the embryo.
\end{abstract}

Plants and animals have each evolved different reproductive strategies that determine the extent to which the parents, usually the female, exert control over the developing offspring. Fertilization can be external or internal. In the latter case, the fertilized egg can be laid on a nutritive substrate (e.g., insects) or it develops within a protective and nurturing matrix (the placenta of mammals, the egg of birds and reptiles, the seed of seed plants). The MZT marks the end of maternal control and the onset of zygotic control over embryo development. It is characterized by the simultaneous degradation of stored maternal products and zygotic genome activation (Andéol 1994; Schultz 2002; Tadros et al. 2003; Stitzel and Seydoux 2007). In animals, the MZT occurs several cell cycles after fertilization. As a consequence, the first stages of embryonic development essentially rely on maternally deposited products. Despite divergent reproductive strategies and differences in the parental provisioning for offspring development, current evidence indicates that plants and animals share a marked maternal control of early postfertilization development. We review this evidence and our knowledge regarding the mechanisms controlling the onset of the MZT in both animals and plants. We hypothesize that shared biological constraints on early embryo development explain the existence of convergent mechanisms for maintaining maternal predominance.

\section{EARLY EMBRYOGENESIS IN ANIMALS AND HIGHER PLANTS}

Embryogenesis in flowering plants and animals has in common the union of a male and a female gamete that produces the zygote and the sequential events of cell proliferation, morphogenesis, and organogenesis that follow (Fig. 1). In animals, a single female gamete, the oocyte, fuses with a motile sperm to produce the zygote. Cell proliferation generates a multicellular morula of 16-32 cells

\footnotetext{
${ }^{\dagger}$ These authors contributed equally to this work.
}

in mammals, a blastula of approximately 30,000 cells in Xenopus, and a syncytial blastoderm of about 6000 nuclei in Drosophila. Cellularization (for the syncytial blastoderm of insects) and asymmetric divisions define the onset of morphogenesis, and cellular migration marks the beginning of gastrulation and organogenesis (Browder et al. 1991).

In flowering plants, two pairs of gametes fuse, a process termed double fertilization. The two female gametes, the egg and central cell, are each fertilized by a sperm to produce the embryo and the endosperm, respectively. The endosperm is a protective and nurturing tissue that has a role similar to that of the placenta in eutherian mammals (Harper et al. 1970). The female gametes are produced together with "accessory" cells (the synergids and antipodals) within the female gametophyte (embryo sac), which is enclosed in the ovule that, after fertilization, forms the seed. Ovule and seed development occurs in the gynoecium in the center of the flower. The two sperms are produced by the male gametophyte (pollen), which germinates and grows through tissues of the gyneocium to deliver the sperm cells to the embryo sac. In plants, the early events of embryo development and pattern formation have been best described in the model plant Arabidopsis thaliana. In contrast to the situation in animals, the first division of the zygote is asymmetric and produces an apical cell, giving rise to the embryo proper, and a basal cell, forming the embryonic suspensor and the hypophysis, which will contribute to the root meristem of the embryo (Park and Harada 2008). The apical and basal cells are distinguished not only by their shape, but also by the differential expression of key regulatory genes (Breuninger et al. 2008). The apical cell then divides symmetrically until the fourth, asymmetric cleavage, which establishes the protoderm, the precursor of the epidermis. Further asymmetrical divisions will set up the apical-basal and radial polarity of the globular-stage embryo that contains about 100 cells. The transition from radial to bilateral symmetry occurs later with the formation of the early heart-stage embryo (Jürgens 1992; Park and Harada 2008). The embryo and endosperm of flowering 
mouse
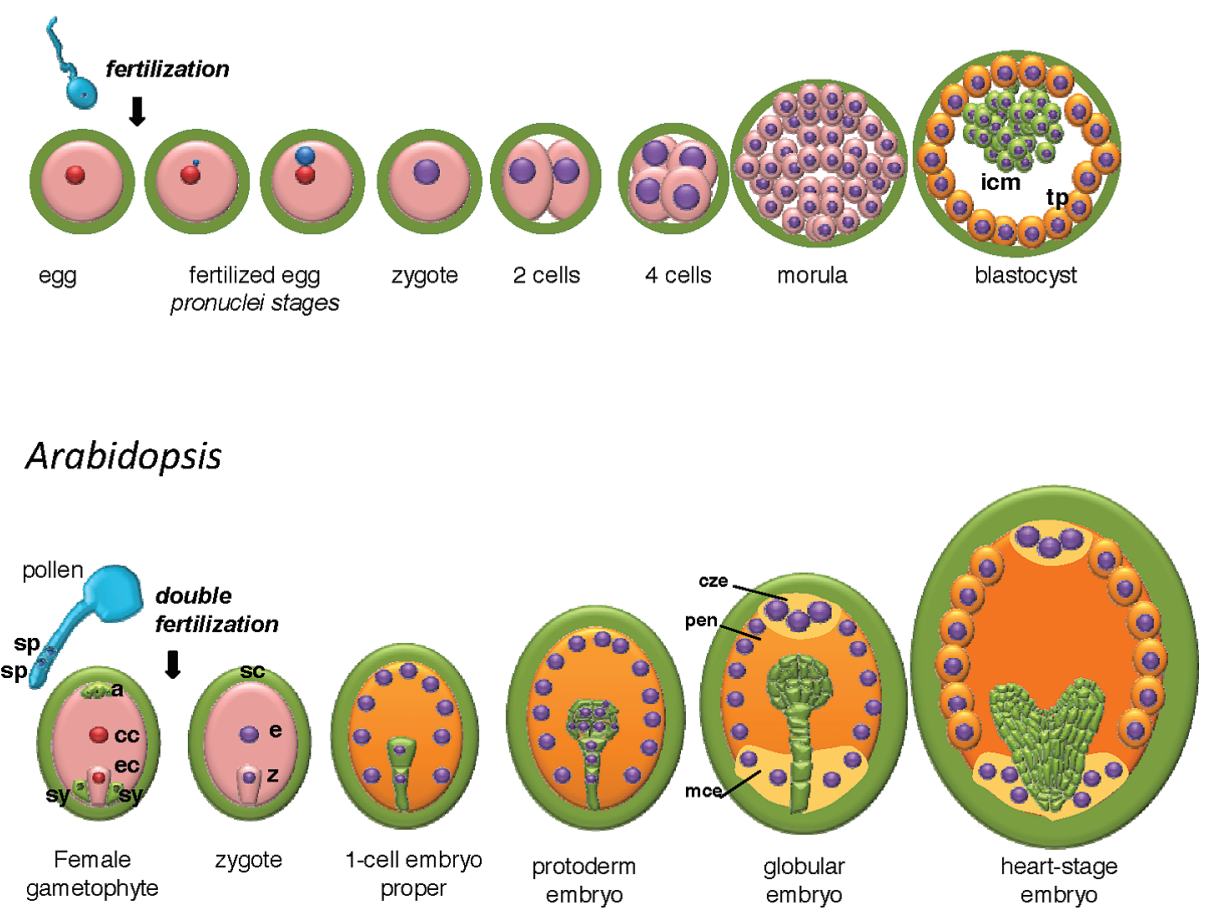

Figure 1. Early development in animals and plants using the mouse and Arabidopsis as models. Sexual reproduction involves dimorphic gametes in both animals and plants, which are highly differentiated. The products of fertilization will undergo several cleavage cycles before morphogenesis. These stages of early development are largely under maternal control. In mammals (e.g., the mouse) symmetrical cleavages form a morula, whereas further asymmetrical cleavages and positioning of daughter cells separate the inner cell mass (icm) from the peripheral trophectoderm (tp), being precursors of the embryo and the placenta, respectively. In flowering plants (e.g., Arabidopsis), double fertilization takes place. It involves two sperm cells (sp) delivered by the pollen to the female gametophyte. The latter consists of seven cells, two of which are the female gametes (the egg [ec] and the central cell [cc]) and the others (synergids [syn] and antipodals [a]) are accessory cells. Double fertilization produces the zygote (z) and the primary endosperm nucleus (e), precursors of the embryo (green) and the endosperm (orange), respectively. Seed stages are defined according to the embryo stage (protoderm, globular, and heart stages only are represented here). The endosperm develops initially as a syncytium. Three mitotic domains are established at the globular stage and are positioned along the anteroposterior axis (chalazal endosperm [cze], peripheral endosperm [pen], micropylar endosperm [mce]). The peripheral endosperm becomes cellularized when the embryo reaches the early heart stage.

plants develop simultaneously and in coordination but along distinct developmental pathways. In Arabidopsis, the endosperm undergoes about ten nuclear division cycles within a syncytium before cellularization occurs and three endosperm domains differentiate along the anteroposterior axis (Brown et al. 1999; Boisnard-Lorig et al. 2001).

\section{MATERNAL CONTROL OF EARLY DEVELOPMENT AND THE MATERNAL TO ZYGOTIC TRANSITION}

\section{Defining the Maternal to Zygotic Transition}

Early development in animals is under maternal control. This was dramatically illustrated by enucleation experiments first conducted on sea urchins by Harvey in 1936. When induced by seawater, enucleated eggs are able to undergo normal cleavages and form plutei, their free swimming larval form (Harvey 1936). Thus, the cleavage stage of the sea urchin relies solely on maternally stored products and does not require the expression of the zygotic genome until the larvae metamorphose into the adult form.
Since Harvey's experiments, it has been found that early development of many animal species-evolutionarily as divergent as echinoderms, amphibians, fishes, worms, insects, birds, and mammals - also relies on maternally deposited products (Andéol 1994). The stage at which maternal reliance ends and control of embryo development is transferred to the zygotic genome is referred to as the MZT. The MZT, under this definition, is distinct from the stage of zygotic genome activation (ZGA), which corresponds to the onset of de novo transcription from the zygotic genome. ZGA and MZT can coincide, but this is not always the case (Table 1). The MZT is also distinct from the midblastula transition (MBT), a developmental transition in amphibians and fishes associated with cell cycle lengthening, asynchronous cleavage, and the acquisition of cell motility, which, however, does not require zygotic transcription (Newport and Kirschner 1982a). The distinction is not always clear in the literature, and the MBT and ZGA are often referred to as marking the MZT, although this is clearly not true in all organisms. In this review, we adhere to a strict distinction as defined above.

Importantly, ZGA is not sufficient to ensure control by 
Table 1. Maternal to zygotic transition and zygotic gene activation in plants and animals

\begin{tabular}{|c|c|c|c|c|}
\hline \multirow[b]{2}{*}{ Organism } & \multicolumn{2}{|c|}{ ZGA } & \multirow[b]{2}{*}{ MZT } & \multirow[b]{2}{*}{ References } \\
\hline & first detection & major ZGA & & \\
\hline \multicolumn{5}{|l|}{ Animals } \\
\hline Sea urchin & $\begin{array}{l}\text { zygote, paternal } \\
\text { pronucleus }\end{array}$ & zygote & $\begin{array}{l}\text { pluteus } \\
\text { (larvae) }\end{array}$ & Harvey (1936); Poccia et al. (1985) \\
\hline C. elegans & four cells & $90-125$ cells & $\begin{array}{l}\text { gastrulation } \\
(\sim 28 \text { cells })\end{array}$ & $\begin{array}{l}\text { Schauer and Wood (1990); Edgar et al. (1994); } \\
\text { Seydoux and Fire (1994) }\end{array}$ \\
\hline Xenopus & $\begin{array}{l}\text { pre-MBT } \\
\quad(\sim 256 \text { cells })\end{array}$ & $\begin{array}{l}\text { MBT } \\
\quad(\sim 4000 \text { cells })\end{array}$ & $\begin{array}{l}\text { blastula } \\
\qquad(\sim 30,000 \text { cells })\end{array}$ & Newport and Kirschner (1982b); Yang et al. (2002) \\
\hline Drosophila & cleavage 8 & $\begin{array}{l}\text { cleavage } 14 \\
\quad(\sim 6000 \text { cells })\end{array}$ & blastoderm & Robbins (1980); Pritchard and Schubiger (1996) \\
\hline Zebra fish & $\begin{array}{l}\text { pre-MBT } \\
\quad(\sim 64 / 128 \text { cells })\end{array}$ & MBT & at epiboly & Kane et al. (1996); Mathavan et al. (2005) \\
\hline Mouse & $\begin{array}{l}\text { zygote, paternal } \\
\text { pronucleus }\end{array}$ & $\begin{array}{l}\text { two-cell } \\
\text { embryo }\end{array}$ & $\begin{array}{l}\text { two-cell } \\
\text { embryo }\end{array}$ & Schultz (2002); Zeng et al. (2004) \\
\hline \multicolumn{5}{|l|}{ Plants } \\
\hline Arabidopsis & two-cell embryo & $\begin{array}{l}\text { globular } \\
\text { embryo }\end{array}$ & $\begin{array}{l}\text { globular } \\
\text { embryo? }\end{array}$ & $\begin{array}{l}\text { Vielle-Calzada et al. (2000); Baroux et al. (2001); } \\
\text { Weijers et al. (2001) }\end{array}$ \\
\hline Maize & zygote & $\begin{array}{l}\text { globular } \\
\text { embryo }\end{array}$ & n.d. & Grimanelli et al. (2005); Meyer and Scholten (2007) \\
\hline Maize IVF & zygote & n.d. & n.d. & $\begin{array}{l}\text { Dresselhaus et al. (1996, 1999); Leduc et al. (1996) } \\
\text { Scholten et al. (2002) }\end{array}$ \\
\hline Wheat & $\begin{array}{l}\text { two-cell } \\
\text { proembryo }\end{array}$ & n.d. & n.d. & Sprunck et al. (2005) \\
\hline Tobacco & zygote & n.d. & n.d. & Ning et al. (2006) \\
\hline
\end{tabular}

ZGA is gradual in animals and plants and can occur concomitantly or earlier than the MZT, as assessed by enucleation experiments (sea urchin), pharmacological treatments (inhibition of RNA pol II with $\alpha$-amanitin), mutant analyzes, or both (other organisms). n.d. indicates not determined; IVF, in vitro fertilization.

the zygotic genome. Although ZGA is a necessary condition, it is not sufficient because the MZT also requires that the maternally stored products no longer influence the further development of the embryo. Regulation of the MZT must thus depend on an appropriate balance between maternal mRNA clearance and ZGA.

\section{Timing of the Maternal to Zygotic Transition in Plants and Animals}

The MZT was originally defined using $\alpha$-amanitin, an inhibitor of RNA polymerase II and III. Application on fertilized eggs or later stages blocks zygotic transcription and the induced developmental arrest marks the MZT. In worms, echinoderms, amphibians, fishes, and insects, the MZT takes place after the entire cleavage period is completed. In particular, in amphibians and fishes, the MZT occurs after the MBT, only at the onset of the first morphogenetic event (Newport and Kirschner 1982a; Stroband et al. 1992; Kane et al. 1996). In contrast, mammalian embryos require zygotic transcription already at the twocell stage (Andéol 1994). The MZT can take place after as few as one cycle (two-cell mouse embryo) or about 15 cell cycles (Xenopus blastula). On an absolute timescale, the MZT occurs between 2 hours (Drosophila nuclear blastoderm) and 2 days (four- to eight-cell human embryo) after fertilization. Thus, the extent of maternal control and the timing of the MZT vary greatly among species.

The timing of the MZT can also be defined genetically. Because the MZT occurs a certain number of division cycles after fertilization, mutations affecting early develop- ment in animals often display maternal effects. Mutations showing a maternal effect can affect a gene product stored in the egg whose function is required between fertilization and the MZT. Alternatively, maternal effects can result from genomic imprinting, as is the case for genes that are zygotically expressed but with only the maternal allele being active and the paternal allele remaining silent. Genetic characterization coupled with parental allele-specific expression analyses is thus required to distinguish the different mechanisms underlying maternal effects. Maternal-effect mutants with a developmental defect before the MZT are informative for the role of maternal factors in early embryo development, for example, in chromatin remodeling and pronuclear congression (Loppin et al. 2001; Dekens et al. 2003) or the definition of body axes (Moody et al. 1996; Pelegri 2003; Mtango et al. 2008). The mutant class informative for zygotic gene contribution after the MZT consists of zygotic maternal mutants, which display a maternal phenotype that is either rescuable by the wild-type paternal allele (recessive mutant) or is enhanced by a mutant paternal allele (dominant mutant). In zebra fish, zygotic maternal mutants have been isolated that show a developmental arrest or delay of epiboly, the first morphogenetic event and the stage of the MZT (Kane et al. 1996), or they affect cell-fate determination processes at later stages of development (Pelegri 2003). Similarly in Drosophila, cell division and patterning genes acting maternally and zygotically have been uncovered in genetic screens (Garcia-Bellido and Robbins 1983; Perrimon et al. 1989, 1996).

Because of their inaccessibility, the plant embryo and 
endosperm are not amenable to pharmacological experiments, such as inhibition of transcription by $\alpha$-amanitin. Thus, genetic approaches have been used to investigate the MZT. However, the analysis of maternal-effect mutants in plants is complicated by the fact that maternal influences on seed development can stem from several possible sources (for review, see Grossniklaus and Schneitz 1998; Chaudhury et al. 2001; Baroux et al. 2002): (1) the intimate relationship of the fertilization products with the surrounding maternal tissues (sporophytic effects), (2) the dominant cytoplasmic contribution of female versus male gametes (gametophytic effects), (3) non-cell-autonomous effects of the endosperm on embryo development, and (4) genomic imprinting as observed in mammals. Thus, genetic characterization, together with thorough expression analyses, has to dissect the contribution of each effect to the observed mutant phenotype.

In plants, very few maternal-effect mutations are informative for the MZT, mostly because relatively few experiments have been conducted to specifically target maternal effects. Thus, very little is known about the nature and role of maternal factors stored in the female gametes. PROLIFERA, an MCM7 protein, is encoded by a maternaleffect gene important for the cell divisions following fertilization (Springer et al. 1995, 2000), but the low penetrance of the mutation suggests a redundant function with other factors. Interestingly, mutations in ORC2, a subunit of the origin recognition complex that, like MCM7, participates in the formation of the prereplicative complex, are suppressed by the maternal-effect mutation medea, further illustrating the interplay of maternal and zygotic factors early in development (Collinge et al. 2004). Arabidopsis MSI1 (MULTISUPPRESSOR of IRA1), which, among others, interacts with the RETINOBLASTOMA-RELATED (RBR) protein regulating the initiation of replication (Ach et al. 1997), is required in the female gametophyte, and not zygotically, to maternally control embryo and endosperm proliferation (Leroy et al. 2007).
Two genetic screens aimed at the isolation of gametophytic mutations identified a number of maternal-effect mutants affecting embryo development at various, often early, stages (Moore 2002; Pagnussat et al. 2005). As outlined above, it is not easy to determine the underlying mechanisms of a maternal effect in plants, and the mode of action of the genes affected in these mutants is currently not known. Large numbers of recessive mutations with zygotic effects have also been isolated, with the embryo phenotype only observed when both parental alleles are defective (Tzafrir et al. 2004). Some of them can affect embryo development at very early stages, including the zygote (Weijers et al. 2001; Lukowitz et al. 2004; Wu et al. 2007; Ronceret et al. 2008). This observation indicates that the paternal genome can complement for a deficient maternal contribution. Although it is generally assumed that such a paternal rescue stems from transcription of the paternally contributed genome, it could also be contributed by the sperm's cytoplasm. In fact, Arabidopsis sperm cells were recently shown to contain a distinct and diverse transcript profile (Borges et al. 2008). Moreover, zygotically acting mutants provide limited information regarding the MZT, because the timing of the paternal rescue is generally unknown. This has rarely been investigated but is illustrated by the mutants gnom/emb30 and vacuoleless1 ( vcll), which were both classified as recessive zygotic embryo lethals. Both heterozygous mutants produce approximately $25 \%$ aborted seeds when screened at a late stage of fruit development (Mayer et al. 1993; Rojo et al. 2001). However, at early stages of embryo development (e.g., two- to four-cell stage), mutant phenotypes are observed at similar frequencies whether self-fertilized or crossed to wild-type pollen (Table 2) (Vielle-Calzada et al. 2000). This indicates that at the two- to four-cell stage, a paternally inherited wild-type allele cannot provide enough activity to rescue the mutant phenotype. Thus, paternal rescue of the maternal mutation occurs later during embryo development. The time course analysis performed for the vcll

Table 2. Delayed paternal rescue of vacuoleless 1 and gnom/emb30

\begin{tabular}{|c|c|c|c|c|c|}
\hline & $\begin{array}{l}\text { Two-four cells } \\
\quad(2 \text { dap })\end{array}$ & $\begin{array}{l}\text { Globular } \\
\text { (3 dap) }\end{array}$ & $\begin{array}{l}\text { Heart } \\
\text { (4 dap) }\end{array}$ & $\begin{array}{l}\text { Late heart } \\
\text { (5 dap) }\end{array}$ & $\begin{array}{l}\text { Mature } \\
\text { seed }\end{array}$ \\
\hline \multicolumn{6}{|l|}{ vacuoleless1/vcl1 } \\
\hline$v c l 1 / V C L 1$ selfed & $\begin{array}{c}53 \% \\
(n=243)\end{array}$ & $\begin{array}{c}25 \% \\
(n=271)\end{array}$ & $\begin{array}{c}16 \% \\
(n=290)\end{array}$ & $\begin{array}{c}20 \% \\
(n=287)\end{array}$ & $\begin{array}{c}25 \% \\
(n=999)\end{array}$ \\
\hline$v c l 1 / V C L 1 \times V C L 1 / V C L 1$ & $\begin{array}{c}38 \% \\
(n=258)\end{array}$ & $\begin{array}{c}12 \% \\
(n=232)\end{array}$ & $\begin{array}{c}1 \% \\
(n=210)\end{array}$ & $\begin{array}{c}0 \% \\
(n=318)\end{array}$ & \\
\hline$V C L 1 / V C L 1 \times v c l 1 / V C L 1$ & $\begin{array}{c}3 \% \\
(n=137)\end{array}$ & $\begin{array}{c}1 \% \\
(n=171)\end{array}$ & $\begin{array}{c}1 \% \\
(n=119)\end{array}$ & $\begin{array}{c}0 \% \\
(n=137)\end{array}$ & \\
\hline \multicolumn{6}{|l|}{ gnom/emb30 } \\
\hline emb30/EMB30 selfed & $\begin{array}{c}12 \% \\
(n=131)\end{array}$ & & & & $\begin{array}{c}25 \% \\
(n=?)^{*}\end{array}$ \\
\hline$e m b 30 / E M B 30 \times E M B 30 / E M B 30$ & $\begin{array}{c}13 \% \\
(n=116)\end{array}$ & & & & $\begin{array}{c}0 \% \\
(n=157)\end{array}$ \\
\hline$E M B 30 / E M B 30 \times e m b 30 / E M B 30$ & $\begin{array}{c}0 \% \\
(n=53)\end{array}$ & & & & \\
\hline
\end{tabular}

vcl1 and wild-type plants were pollinated 2 days after emasculation, and embryos were scored at 2, 3, 4, and 5 days after pollination (dap); seeds were cleared as described previously (Rojo et al. 2001). The frequency of emb30-3 mutant embryos is cited from VielleCalzada et al. (2000) except for (*), which is cited from www.arabidopsis.org (lethal phenotype curated by ABRC). The percentage of mutant embryos is shown, with the total number examined in parentheses. For each cross, the female genotype is listed first. 
mutation (Table 2) suggests that the maternally driven mutant phenotype is gradually rescued by the paternal allele and that the MZT in Arabidopsis takes place between the two- to four-cell stage and the globular stage. Additional reassessments of existing recessive embryo lethal mutants arrested at late stages would allow defining the MZT with more precision.

\section{ZYGOTIC GENE ACTIVATION}

\section{Zygotic Genome Activation Precedes the Maternal to Zygotic Transition and Is Gradual}

ZGA was initially defined as the stage where a large increase in de novo RNA synthesis could be measured, for instance, following the incorporation of radioactivelabeled uridine or adenosine (Zalokar 1976; Clegg and Piko 1977). However, it was early recognized that specific transcripts such as $\alpha$-histone mRNA, selective species of rRNA or tRNA could be synthesized de novo before the major ZGA (Anderson and Lengyel 1980). Furthermore, microinjection of reporter genes, as done in Xenopus and mouse embryos (Newport and Kirschner 1982b; Telford et al. 1990), elegantly demonstrated the developmental acquisition of transcriptional capacity before the major ZGA. Since then, additional examples of zygotic genes expressed before the major ZGA in Drosophila, but also in Xenopus, zebra fish, mouse, and Caenorhabditis elegans, established that ZGA is a gradual process (see Table 1). Recent profiling experiments comparing $\alpha$-amanitin-sensitive and $\alpha$ amanitin-insensitive genes (differentiating de novo from maternally deposited transcripts) confirmed that a large number of zygotic genes are already active at the one-cell stage in the mouse embryo with a selective, although abundant, activation of genes involved in transcription and RNA processing at the two-cell stage (Zeng et al. 2004). Such early expressed genes are likely to have a specific role in the MZT itself. This view is supported by the observation that in Drosophila, but also in Xenopus and C. elegans, early inhibition of zygotic gene transcription (using $\alpha$ amanitin) prolongs maternally driven embryonic development in comparison to blocking the major ZGA by a treatment just before the MZT (for review, see Andéol 1994). It was suggested that early expressed genes, such as the Drosophila string gene, may also have an important role in controlling the degradation of maternally stored transcripts (Edgar and Lehner 1996). The recent identification of the zinc finger protein Zelda, a regulator of ZGA in Drosophila, confirms this scenario (Liang et al. 2008).

ZGA coincides with the MZT in mouse and Drosophila embryos (Andéol 1994). However, ZGA precedes the MZT in amphibians or fishes by several cell cycles (Table 1). In the sea urchin, where the zygote has no transcriptional quiescence, this difference is even more dramatic. Importantly, even in these animal species, ZGA is a gradual process with a subset of genes being activated early before the dramatic increase in transcription at the major ZGA.

Similar experiments of ZGA have not been performed in plants, where the developing embryo is deeply embedded in maternal tissues that act as a barrier for pharmacological treatments. It is also difficult, as in animals, to discriminate maternally stored from de-novo-synthesized zygotic transcripts in fertilization products. This could be done by looking at nascent transcripts performing RNA-FISH (fluorescence in situ hybridization) on developing embryos, as was done in Drosophila, for instance (Ronshaugen and Levine 2004). To date, similar techniques have only been applied to the Arabidopsis endosperm, where the maternally expressed, imprinted $M E D E A$ locus was found to be actively transcribed immediately following fertilization (Vielle-Calzada et al. 1999). One route around this problem is to analyze the activation of paternally inherited alleles as a substitute for zygotic gene expression, albeit with provisions regarding the synchronous activation of both parental genomes (see later in the text). In Arabidopsis and maize, the activation of paternal genes has been followed using reporter transgenes, allele-specific reverse transcriptase-polymerase chain reaction (RT-PCR), or both, for a discrete number of loci. It was found that most paternal loci remained silent or were expressed at very low levels until the globular embryo stage (Vielle-Calzada et al. 2000; Baroux et al. 2001; Grimanelli et al. 2005). Importantly, the verification of paternal activation of endogenous genes using allele-specific RT-PCR excluded transgene-specific paternal silencing effects. This finding was corroborated in maize, where transcript profiles from sexually produced seeds were compared with profiles from seeds of exclusively maternal origin (generated through asexual reproduction) (Grimanelli et al. 2005). The results indicate major changes in the transcript profile only around the globular stage of embryogenesis. A ZGA only after several division cycles was confirmed in Arabidopsis by the observation of delayed expression for several other paternally inherited transgenes, or endogenous genes, in unrelated reports (Table 3). Importantly, a delay in paternal gene expression is observed in both the embryo and endosperm.

Interestingly, as in animals, several genes are zygotically active before the major stage of paternal genome activation as defined above. A few paternally inherited alleles were found to be expressed already in two-cell Arabidopsis embryos (Weijers et al. 2001), albeit at low levels (Baroux et al. 2001). Early activation is more prominent in maize. Embryo-expressed genes were shown to be expressed biallelically in the zygote using allele-specific assays on manually dissected maize zygotes and embryos (Meyer and Scholten 2007). Although for 13 of the 25 genes tested, there was no significant difference in the levels of maternally and paternally derived transcripts in the zygote, paternal activation is not complete at this stage for other loci. At the zygote stage, 10 of 25 genes showed predominantly maternal expression, decreasing to 8 of 25 loci at 3 days after pollination and to 5 of 25 loci at 6 days after pollination (Meyer and Scholten 2007). Thus, maternal predominance decreases gradually because either paternal alleles are increasingly more transcribed or maternal transcripts are degraded, or both.

Therefore, as in animals, ZGA seems to be a gradual process in higher plants. Differences between maize and Arabidopsis seem to exist, however, up to the earliest stage at which zygotic genes can be detected. This discrepancy may relate to different reproductive strategies. Out-crossing plants, such as maize, may benefit significantly from heterosis effects related 
Table 3. Reported examples of predominant maternal expression in the early embryo and/or endosperm of higher plants

\begin{tabular}{|c|c|c|}
\hline Locus (gene or transgene) & Method of investigation & Reference \\
\hline \multicolumn{3}{|l|}{ Arabidopsis } \\
\hline$A G P 18$ & $\begin{array}{l}\text { allele-specific RT-PCR/ } \\
\text { enhancer detector }\end{array}$ & our unpublished observations \\
\hline $\begin{array}{l}\text { AtLPT1:GUS, } \\
\quad \text { AtLTP1:LhG4) }\end{array}$ & reporter expression & Baroux et al. (2001 \\
\hline AtSUC5 & $\begin{array}{l}\text { allele-specific RT-PCR/ } \\
\text { reporter expression }\end{array}$ & our unpublished observations \\
\hline $\begin{array}{l}C Y C B 1 ; 1: G U S, \\
\quad C B C B 1 ; 1: L h G 4\end{array}$ & reporter expression & Baroux et al. (2001) \\
\hline DCL1:GUS & reporter expression & Golden et al. (2002) \\
\hline DD36 & reporter expression & our unpublished observations \\
\hline ET346 & enhancer detector & Vielle-Calzada et al. (2000) \\
\hline ET552 & enhancer detector & Vielle-Calzada et al. (2000) \\
\hline ET1041 & enhancer detector & Vielle-Calzada et al. (2000) \\
\hline ET1051 & enhancer detector & Vielle-Calzada et al. (2000) \\
\hline ET1119 & enhancer detector & Vielle-Calzada et al. (2000) \\
\hline ET1275 & enhancer detector & Vielle-Calzada et al. (2000) \\
\hline ET1278 & enhancer detector & Vielle-Calzada et al. (2000) \\
\hline ET1811 & enhancer detector & Vielle-Calzada et al. (2000) \\
\hline ET1849 & enhancer detector & Vielle-Calzada et al. (2000) \\
\hline ET2209 & enhancer detector & Vielle-Calzada et al. (2000) \\
\hline ET2567 & enhancer detector & Vielle-Calzada et al. (2000) \\
\hline ET2612 & enhancer detector & Vielle-Calzada et al. (2000) \\
\hline ET2634 & enhancer detector & Vielle-Calzada et al. (2000) \\
\hline ET3536 & enhancer detector & Vielle-Calzada et al. (2000) \\
\hline ET3757 & enhancer detector & Vielle-Calzada et al. (2000) \\
\hline ET3988 & enhancer detector & Vielle-Calzada et al. (2000) \\
\hline ET3992 & enhancer detector & Vielle-Calzada et al. (2000) \\
\hline ET4320 & enhancer detector & Vielle-Calzada et al. (2000) \\
\hline ET4336 & enhancer detector & Vielle-Calzada et al. (2000) \\
\hline ET4563 & enhancer detector & Vielle-Calzada et al. (2000) \\
\hline FIE:GUS, FIE:GFP & reporter expression & Yadegari et al. (2000) \\
\hline GNOM/EMB30 & allele-specific RT-PCR & Vielle-Calzada et al. (2000) \\
\hline KS117 & reporter expression & Sørensen et al. (2001) \\
\hline LACHESIS:GUS & reporter expression & our unpublished observations \\
\hline MSI1 & allele-specific RT-PCR & Leroy et al. (2007) \\
\hline$p O p / L h G 4$ components & reporter expression & Baroux et al. 2001) \\
\hline PROLIFERA & $\begin{array}{l}\text { allele-specific RT-PCR/ } \\
\text { enhancer detector/gene trap }\end{array}$ & $\begin{array}{l}\text { Springer et al. (2000); } \\
\text { Vielle-Calzada et al. (2000) }\end{array}$ \\
\hline \multicolumn{3}{|l|}{ Zea mays } \\
\hline AB073081 & allele-specific RT-PCR & Grimanelli et al. (2005) \\
\hline AF371278 & allele-specific RT-PCR & Grimanelli et al. (2005) \\
\hline AI670662 & allele-specific RT-PCR & Grimanelli et al. (2005) \\
\hline AI677212 & allele-specific RT-PCR & Grimanelli et al. (2005) \\
\hline AI677270 & allele-specific RT-PCR & Grimanelli et al. (2005) \\
\hline AI745997 & allele-specific RT-PCR & Grimanelli et al. (2005) \\
\hline AI746088 & allele-specific RT-PCR & Grimanelli et al. (2005) \\
\hline AI746192 & allele-specific RT-PCR & Grimanelli et al. (2005) \\
\hline AI833700 & allele-specific RT-PCR & Grimanelli et al. (2005) \\
\hline AI854929 & allele-specific RT-PCR & Grimanelli et al. (2005) \\
\hline AW066244 & allele-specific RT-PCR & Grimanelli et al. (2005) \\
\hline AW066927 & allele-specific RT-PCR & Grimanelli et al. (2005) \\
\hline AW091461 & allele-specific RT-PCR & Grimanelli et al. (2005) \\
\hline AW181192 & allele-specific RT-PCR & Grimanelli et al. (2005) \\
\hline AW216004 & allele-specific RT-PCR & Grimanelli et al. (2005) \\
\hline AW216025 & allele-specific RT-PCR & Grimanelli et al. (2005) \\
\hline AW216194 & allele-specific RT-PCR & Grimanelli et al. (2005) \\
\hline DW475554 & MS on RT-PCR products & Meyer and Scholten (2007) \\
\hline EH038205 & MS on RT-PCR products & Meyer and Scholten (2007) \\
\hline EH038208 & MS on RT-PCR products & Meyer and Scholten (2007) \\
\hline EH038209 & MS on RT-PCR products & Meyer and Scholten (2007) \\
\hline EH038210 & MS on RT-PCR products & Meyer and Scholten (2007) \\
\hline EH038211 & MS on RT-PCR products & Meyer and Scholten (2007) \\
\hline EH038212 & MS on RT-PCR products & Meyer and Scholten (2007) \\
\hline EH038213 & MS on RT-PCR products & Meyer and Scholten (2007) \\
\hline EH038215 & MS on RT-PCR products & Meyer and Scholten (2007) \\
\hline EH038218 & MS on RT-PCR products & Meyer and Scholten (2007) \\
\hline Fie2 & allele-specific RT-PCR & Danilevskaya et al. (2003) \\
\hline Megl & allele-specific RT-PCR & Gutiérrez-Marcos et al. (2004) \\
\hline
\end{tabular}

Genes or transgenes (enhancer detectors, reporter gene fusions, components of gene transactivation systems) are listed, together with methods used to discriminate the expression of parental alleles for the two species Arabidopsis and maize. Putative or known functions assigned to these genes do not suggest any common trend with respect to their cellular functions. (MS) Mass spectrometry. 
to early paternal genome activation (Meyer and Scholten 2007), but no heterosis effects are observed in embryos of self-fertilizing species, such as Arabidopsis, at this early stage.

\section{Mechanisms of Zygotic Genome Activation}

Establishment of a permissive chromatin state. Following fertilization in mammals, reprogramming of chromatin occurs on a large scale by rapid and active demethylation of the paternal genome, whereas the maternal genome is progressively and passively demethylated (Santos et al. 2002). Imprinted genes, however, escape these demethylation processes (Branco et al. 2008). Genome-wide demethylation reflects the release of a global, silent chromatin state, a prerequisite for transcriptional activation. Furthermore, the apparent increase in histone acetylation at the one- to twocell transition in the mouse may provide the basis for a permissive transcription state (Sarmento et al. 2004). In favor of this argument, depletion of maternal BRG1, a catalytic subunit of SWI/SNF-related chromatin remodeling complexes, does not affect global levels of histone acetylation, but affects levels of $\mathrm{H} 3 \mathrm{~K} 4 \mathrm{me} 2$, a mark of active chromatin (Bultman et al. 2006). Maternal depletion of BRG1 causes embryos to arrest at the MZT (two-cell arrest) and results in down-regulation of $30 \%$ of the genes that are normally expressed at this stage. Maternal mutations in the mouse homolog of Xenopus nucleoplasmin 2 (NPM2), which induces sperm DNA decondensation in vitro, lead to a loss of heterochromatin and deacetylated histone $\mathrm{H} 3$ associated with nucleoli (Burns et al. 2003). However, the exact role of maternal NPM2 in regulating zygotic gene expression levels is not known.

During this reprogramming process, repressive mechanisms also act to ensure relative embryonic quiescence. The role of transcriptional repressors has been uncovered by conditional inhibition of protein synthesis during embryo development. This is the case for the Xenopus homolog of the mammalian DNA-methyltransferase Dnmt1 (xDnmt1), where embryos deficient in $\mathrm{xDnmt} 1$ exhibit premature gene expression at least two cell cycles earlier than normal (Stancheva and Meehan 2000; Stancheva et al. 2002). Repression by $\mathrm{xDnmt1}$ is independent of its catalytic activity, and it may act as a general DNA-binding transcriptional repressor (Dunican et al. 2008). Similarly, the methyl-CpGbinding protein KAISO was identified as a global transcriptional repressor of early transcription in Xenopus (Ruzov et al. 2004). In KAISO-depleted embryos, 35S-UTP incorporation was detected two cell cycles earlier than in mock injected embryos, which was associated with a developmental arrest similar to that observed in embryos depleted for $\mathrm{xDnmt1}$.

The timing of ZGA results, therefore, from a fine-tuned balance between chromatin-based repressive mechanisms and the establishment of a chromatin state permissive for transcription. Silencing and activating epigenetic pathways acting at the genome-wide scale are well described in plants (for review, see Vaillant and Paszkowski 2007). In Arabidopsis, these include DNA methylation at symmetric CG sites controlled by the maintenance of methyltransferase MET1, DNA methylation at non-CG sites (a plant-specific modification) controlled by CMT3 (CHROMOMETHYLASE3), which involves RNA-dependent DNA methylation linking the chromatin small interfering RNA (siRNA)-dependent pathway with DNA methylation, and histone $\mathrm{H} 3$ methylation on lysine 9 (H3K9me2). The potential role of these pathways in early zygote transcriptional silencing and the MZT remains to be determined.

Transcriptional activation of zygotic genes. Genomewide studies identified cis-regulatory elements in the $5^{\prime}$ region of zygotically transcribed genes in Drosophila, which may prime them for expression during early cleavage stages (ten Bosch et al. 2006; De Renzis et al. 2007). The genes possessing the heptamer motif "CAGGTAG" in their 5'-regulatory regions are referred to as "TAG genes" and suggest a collective control of their expression during ZGA by a sequence-specific transcriptional activator(s). This motif was used as an entry point to identify the Zelda (Zld) transcription factor, in a one-hybrid screen (Liang et al. 2008). Zld is maternally stored in the zygote and is required for normal cell division and patterning of the embryo. The broad range of phenotypes observed in zld mutants indicates that $z l d$ embryos fail to express genes essential for cellular blastoderm formation. This was confirmed for several patterning genes by in situ hybridization, and microarray analyses detected at least 279 genes controlled by Zld. Among these, $82 \%$ were zygotically active genes. Surprisingly, an equal amount of genes are up-regulated in zld mutants and correspond to maternal genes. This effect can be explained by a lack of maternal transcript turnover due to the expression of miR309, a target of Zld that is derepressed in mutant zld embryos. Zld therefore provides a mechanistic link between ZGA and maternal transcript degradation (see below and Fig. 2).

Parent-specific mechanisms. Differences in parental genome activation have been observed and can be related to the distinct epigenetic control of maternal and paternal chromosomes. In the mouse, the paternal pronucleus shows transcriptional activity as early as the one-cell stage, before the maternal pronucleus, based on BrUTP incorporation (Aoki et al. 1997). Differential DNA methylation profiles have been found between the two parental genomes in mammals: The maternal genome undergoes a stepwise passive demethylation (see above), whereas the paternal genome is rapidly demethylated before the first cell division (Reik 2007). Moreover, genome-wide analysis of DNA methylation in promoters using mouse embryonic stem cells, embryonic germ cells, and sperm cells shows that their DNA methylation patterns are surprisingly similar. This suggests that although the sperm is a highly specialized and differentiated cell type, its epigenome is already largely reprogrammed before fertilization, resembling that of a pluripotent state (Farthing et al. 2008). Moreover, in contrast to the female genome, the male genome must undergo drastic chromatin remodeling after fertilization. The protamines, which are required for tight chromatin packaging in the sperm, have to be replaced by histones, including H3.3 variants. These histone variants have been associated with transcriptionally active chromatin in animals. The distinct chromatin composition of male and female genomes at 

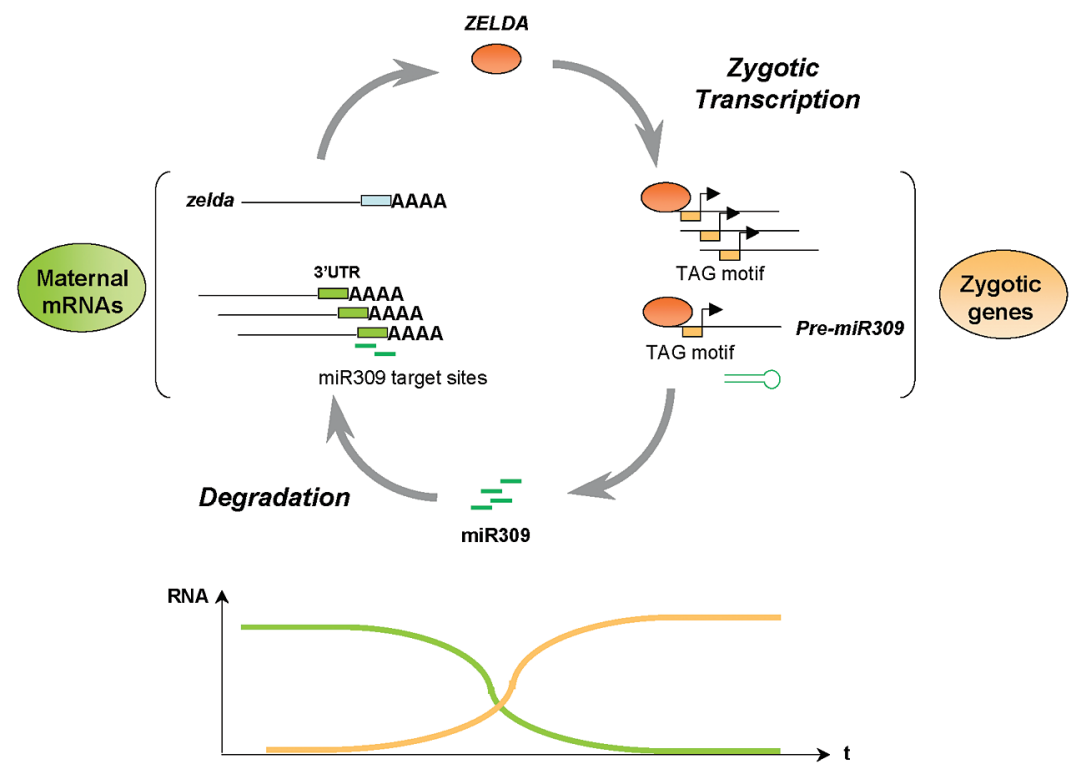

Figure 2. Mechanisms of zygotic genome activation and maternal transcript degradation in Drosophila. Early development is driven by maternal transcripts deposited in the egg. Zelda transcripts are inherited maternally and encode a global transcription factor that recognizes a specific regulatory motif called "TAG." Genes containing the TAG motif in their regulatory regions are transcribed actively in the early embryo after fertilization. Several hundred TAG genes have been identified. Among these, the precursor of microRNAmiR309 (pre-miR309) allows the coupling of zygotic transcriptional activation to the large-scale degradation of maternal transcripts. miR309 targets hundreds of maternally deposited transcripts, inducing their translational inhibition and destabilization. This coupling results in the coordinated decrease and increase in levels of maternal and zygotic transcripts, respectively.

fertilization may provide a mechanistic basis for parentally distinct transcriptional activation mechanisms.

As in animals, the plant sperm chromatin is highly compacted at fertilization. Sperm-specific histone variants have been identified that may package plant sperm genomes similar to the animal protamins (Okada et al. 2005). In Arabidopsis, karyogamy is quickly followed by the removal of at least one of these histones, an H3.3 variant (Ingouff et al. 2007). Interestingly, this removal follows distinct dynamics in the two fertilization products, with a rapid elimination in the zygote and a progressive dilution through successive replication rounds in the endosperm (Ingouff et al. 2007). These findings suggest that changes in core nucleosome composition occur in plants after fertilization, indicating a converging role in plants and animals for histone $\mathrm{H} 3$ and its variants in enabling transcription from paternally inherited chromatin.

\section{OVERCOMING MATERNAL DOMINANCE: DEGRADATION OF MATERNAL FACTORS DURING THE MATERNAL TO ZYGOTIC TRANSITION}

The establishment of the zygotic transcriptional program requires the degradation of maternally contributed RNAs. Although some of the maternal mRNAs are stable and continue to contribute to development long after ZGA, degradation mechanisms start to act early after fertilization, creating a mixed maternal/zygotic gene expression profile in the young embryo. Genome-wide profiling in Drosophila showed that $33 \%$ of the maternally deposited transcripts are degraded in the embryo (De Renzis et al. 2007). Two RNA degradation pathways are used to promote turnover of maternal transcripts during the MZT, and both target 3'UTR (untranslated region) sequence motifs (for review, see Stitzel and Seydoux 2007; Tadros et al. 2007a). The first pathway is driven by maternally encoded factors, whereas the second coincides with the onset of zygotic transcription.

A survey of 1095 genes known to be maternally deposited before the Drosophila MZT identified two families of motifs in their 3'UTR, based on sequence similarity (De Renzis et al. 2007). The first family contains a UUGUU core, which resembles the target site for the PUF family of RNA-binding proteins, represented by the Pumilio translational regulator (Wharton et al. 1998). Pumilio controls the expression of the maternally encoded SMAUG protein, which recognizes stem-loop structures present in 3'UTR or coding sequences of maternal mRNAs (Tadros et al. 2007a; Semotok et al. 2008). Microarray analysis showed that Smaug is a general activator of RNA degradation (Tadros et al. 2007b). Sequences from the second family match the AU-rich element (AREs, canonically defined as UAUUUAU), a mediator of mRNA degradation (Shaw and Kamen 1986). The existence of the zygotic degradation pathway was first demonstrated for the maternal mRNAs of the string/Cdc25 and cyclinA1 cell cycle regulators. Inhibition of transcription in the early embryo by $\alpha$-aminitin treatment inhibited mRNA degradation, thus showing that ZGA and maternal mRNA degradation are coupled during the MZT (Anderson et al. 2001; Audic et al. 2002). It was proposed that a ribonuclease activity 
was responsible for this coupling (Andéol 1994). The regulatory pathway became more intricate with the discovery that regulation by microRNAs (miRNAs) is involved in mRNA degradation during early embryogenesis. miRNAs are small noncoding RNAs, produced from precursors by the Dicer ribonuclease. They silence gene expression by repressing translation or promoting mRNA turnover, via 3'UTR sequence-specific recognition of their target mRNAs. Zebra fish dicer mutants, which lack mature miRNAs, show a maternal zygotic effect (Mishima et al. 2006). In zebra fish, a single miRNA family (miR430) drives the repression of several hundreds of maternal mRNAs (Giraldez et al. 2006). miR430 is expressed zygotically shortly after fertilization and is required for embryogenesis to be completed, as shown by reversion of the dicer embryo phenotype by miR430 injection. miR430 promotes target mRNA clearance by accelerating deadenylation (Giraldez et al. 2006). Use of miRNAs to promote mRNA turnover during the MTZ appears to be a conserved phenomenon because a comparable role of miRNAs was recently reported in Drosophila (Bushati et al. 2008). A cluster of zygotically expressed miRNAs (miR309), activated about 2 hours after fertilization, targets maternal mRNAs for turnover as part of the zygotic degradation pathway. Interestingly, it was recently shown that miR309 zygotic expression is driven by the general ZGA activator Zelda (Fig. 2), providing a link between both the genome activating pathway and the mRNA degrading pathway.

In plants, nothing is known about the mechanisms that lead to a reduction of the maternal dominance at the MZT. A genome-wide analysis of maternal transcripts and their dynamic levels following fertilization would be a prerequisite to identify potential motifs and regulators of their degradation, as was done in Drosophila (Liang et al. 2008). Such studies are challenging because female gametes and fertilization products are embedded in maternal tissues and are difficult to access. This may, however, be overcome using manual or laser-assisted dissection of eggs and young embryos (Dresselhaus et al. 1996, 1999; Day et al. 2005; Sprunck et al. 2005; Meyer and Scholten 2007 ) in combination with transcript profiling or deep sequencing approaches.

\section{BIOLOGICAL SIGNIFICANCE}

Gametes are highly differentiated cells and perform unique tasks associated with reproduction. At the same time, they can rapidly lose gametic cell fate following fertilization and endow the zygote with a totipotent state. Performing both functions implies a dramatic reprogramming of the zygotic genome in order to erase the marks associated with gametic cell fate and to establish the transcriptional status associated with totipotency. The consensus today is that the potential for totipotency in both animals and plants is maternally controlled, with most of the control over genome structure and function residing in the egg cytoplasm (Stitzel and Seydoux 2007). The most striking evidence is the ability of parthenogenetic plants and animals to develop functional organisms without any paternal contribution. That male contributions to the zygote are fully dispensable in these cases illustrates that the female genome maintains enough flexibility to compensate for any essential male contribution, whenever missing. Thus, the oocyte probably drives the events required for totipotency, including the reprogramming of the male genome following fertilization. This is well illustrated by the replacement of paternal histone components by maternally provided histone variants immediately following fertilization.

In animals, this model appears to be true whether the germ line is "predetermined" as in C. elegans or Drosophila (primordial germ cells are formed early through inheritance of maternal germplasm) or formed by inductive signals later during development, such as in mice. In both systems, transcriptional repression in the germ line is apparently decisive to totipotency (Stitzel and Seydoux 2007). In addition, gene regulation is dependent on cytoplamic posttranscriptional mechanisms in both of these systems. Although the underlying processes are different in C. elegans, Drosophila, or mice, shared developmental constraints associated with genome reprogramming and the acquisition of totipotency have led to a set of convergent mechanisms. Transcriptional repression and extensive chromatin remodeling in the gametes are followed by the establishment of a totipotent zygotic program after fertilization through another wave of chromatin reprogramming, and finally, at the MZT, the maternally stored gene products are cleared in the developing embryo.

It is tempting to speculate that the transfer of gene expression to the cytoplasm and the maintenance of relative quiescence in the early embryo represent a buffering mechanism that protects the embryo against uncoordinated genic activity during this dramatic phase of reprogramming. Likely, all living organisms share this constraint, and most animals have apparently responded by evolving remarkably similar mechanisms. Plants more resemble mice than flies, in the sense that they differentiate a germ line very late during development in an inductive manner, often many years after the formation of the embryo. Although the life cycles of plants and animals differ in important ways, the requirement for a reprogramming phase after fertilization remains. Although the data currently available remain inconclusive, we anticipate that the coming years will provide ample opportunities for enriching comparisons between the earliest phase of postfertilization development in animals and that in plants.

\section{ACKNOWLEDGMENTS}

We thank Stephanie Meyer and Stefan Scholten (Universität Hamburg) for their help in identifying loci showing bi-parental expression but maternal dominance in maize zygotes and Chris Somerville (Carnegie Institution) in whose laboratory C.S.G. collected the data on $v$ cll shown in Table 2. C.B. and U.G. are supported by the Swiss National Science Foundation and the University of Zürich; D.A. and D.G. are supported by the Institut de Recherche pour le Développement and Agence National de la Recherche. 


\section{REFERENCES}

Ach, R.A., Taranto, P., and Gruissem, W. 1997. A conserved family of WD-40 proteins binds to the retinoblastoma protein in both plants and animals. Plant Cell 9: 1595-1606.

Andéol, Y. 1994. Early transcription in different animal species: Implication for transition from maternal to zygotic control in development. Roux Arch. Dev. Biol. 204: 3-10.

Anderson, J.E., Matteri, R.L., Abeydeera, L.R., Day, B.N., and Prather, R.S. 2001. Degradation of maternal cdc25c during the maternal to zygotic transition is dependent upon embryonic transcription. Mol. Reprod. Dev. 60: 181-188.

Anderson, K.V. and Lengyel, J.A. 1980. Changing rates of histone mRNA synthesis and turnover in Drosophila embryos. Cell 21: 717-727.

Aoki, F., Worrad, D.M., and Schultz, R.M. 1997. Regulation of transcriptional activity during the first and second cell cycles in the preimplantation mouse embryo. Dev. Biol. 181: 296-307.

Audic, Y., Garbrecht, M., Fritz, B., Sheets, M.D., and Hartley, R.S. 2002. Zygotic control of maternal cyclin A1 translation and mRNA stability. Dev. Dyn. 225: 511-521.

Baroux, C., Blanvillain, R., and Gallois, P. 2001. Paternally inherited transgenes are down-regulated but retain low activity during early embryogenesis in Arabidopsis. FEBS Lett. 509: 1116.

Baroux, C., Spillane, C., and Grossniklaus, U. 2002. Genomic imprinting during seed development. Adv. Genet. 46: 165-214.

Boisnard-Lorig, C., Colon-Carmona, A., Bauch, M., Hodge, S., Doerner, P., Bancharel, E., Dumas, C., Haseloff, J., and Berger, F. 2001. Dynamic analyses of the expression of the HISTONE::YFP fusion protein in Arabidopsis show that syncytial endosperm is divided in mitotic domains. Plant Cell 13: 495509.

Borges, F., Gomes, G., Gardner, R., Moreno, N., McCormick, S., Feijó, J.A., and Becker, J.D. 2008. Comparative transcriptomics of Arabidopsis sperm cells. Plant Physiol. 148: 1168-1181.

Branco, M.R., Oda, M., and Reik, W. 2008. Safeguarding parental identity: Dnmt1 maintains imprints during epigenetic reprogramming in early embryogenesis. Genes Dev. 22: 1567-1571.

Breuninger, H., Rikirsch, E., Hermann, M., Ueda, M., and Laux, T. 2008. Differential expression of $W O X$ genes mediates apicalbasal axis formation in the Arabidopsis embryo. Dev. Cell 14: 867-876.

Browder, L.W., Erickson, C.A., and Jeffery, W.R. 1991. Developmental biology. Saunders, Philadelphia.

Brown, R.C., Lemmon, B.E., Nguyen, H., and Olsen, O.-A. 1999. Development of endosperm in Arabidopsis thaliana. Sex. Plant Reprod. 12: 32-42.

Bultman, S.J., Gebuhr, T.C., Pan, H., Svoboda, P., Schultz, R.M., and Magnuson, T. 2006. Maternal BRG1 regulates zygotic genome activation in the mouse. Genes Dev. 20: 1744-1754.

Burns, K.H., Viveiros, M.M., Ren, Y., Wang, P., DeMayo, F.J., Frail, D.E., Eppig, J.J., and Matzuk, M.M. 2003. Roles of NPM2 in chromatin and nucleolar organization in oocytes and embryos. Science 300: 633-636.

Bushati, N., Stark, A., Brennecke, J., and Cohen, S.M. 2008. Temporal reciprocity of miRNAs and their targets during the maternal-to-zygotic transition in Drosophila. Curr. Biol. 18: 501-506.

Chaudhury, A.M., Koltunow, A., Payne, T., Luo, M., Tucker, M.R., Dennis, E.S., and Peacock, W.J. 2001. Control of early seed development. Annu. Rev. Cell Dev. Biol. 17: 677-699.

Clegg, K.B. and Piko, L. 1977. Size and specific activity of the UTP pool and overall rates of RNA synthesis in early mouse embryos. Dev. Biol. 58: 76-95.

Collinge, M.A., Spillane, C., Köhler, C., Gheyselinck, J., and Grossniklaus, U. 2004. Genetic interaction of an origin recognition complex subunit and the Polycomb group gene MEDEA during seed development. Plant Cell 16: 1035-1046.

Danilevskaya, O.N., Hermon, P., Hantke, S., Muszynski, M.G., Kollipara, K., and Ananiev, E.V. 2003. Duplicated fie genes in maize: Expression pattern and imprinting suggest distinct functions. Plant Cell 15: 425-438.

Day, R.C., Grossniklaus, U., and Macknight, R.C. 2005. Be more specific! Laser-assisted microdissection of plant cells. Trends Plant Sci. 10: 397-406.

Dekens, M.P., Pelegri, F.J., Maischein, H.M., and NüssleinVolhard, C. 2003. The maternal-effect gene futile cycle is essential for pronuclear congression and mitotic spindle assembly in the zebrafish zygote. Development 130: 3907-3916.

De Renzis, S., Elemento, O., Tavazoie, S., and Wieschaus, E.F. 2007. Unmasking activation of the zygotic genome using chromosomal deletions in the Drosophila embryo. PLoS Biol. 5: e117.

Dresselhaus, T., Cordts, S., and Lörz, H. 1999. A transcript encoding translation initiation factor eIF-5A is stored in unfertilized egg cells of maize. Plant Mol. Biol. 39: 1063-1071.

Dresselhaus, T., Hagel, C., Lörz, H., and Kranz, E. 1996. Isolation of a full-length cDNA encoding calreticulin from a PCR library of in vitro zygotes of maize. Plant Mol. Biol. 31: 23-34.

Dunican, D.S., Ruzov, A., Hackett, J.A., and Meehan, R.R. 2008. $\mathrm{xDnmt1}$ regulates transcriptional silencing in pre-MBT Xenopus embryos independently of its catalytic function. Development 135: 1295-1302.

Edgar, B.A. and Lehner, C.F. 1996. Developmental control of cell cycle regulators: A fly's perspective. Science 274: 1646-1652.

Edgar, L.G., Wolf, N., and Wood, W.B. 1994. Early transcription in Caenorhabditis elegans embryos. Development 120: 443451.

Farthing, C.R., Ficz, G., Ng, R.K., Chan, C.F., Andrews, S., Dean, W., Hemberger, M., and Reik, W. 2008. Global mapping of DNA methylation in mouse promoters reveals epigenetic reprogramming of pluripotency genes. PLoS Genet. 4: e1000116.

Garcia-Bellido, A. and Robbins, L.G. 1983. Viability of female germ-line cells homozygous for zygotic lethals in Drosophila melanogaster. Genetics 103: 235-247.

Giraldez, A.J., Mishima, Y., Rihel, J., Grocock, R.J., Van Dongen, S., Inoue, K., Enright, A.J., and Schier, A.F. 2006. Zebrafish MiR-430 promotes deadenylation and clearance of maternal mRNAs. Science 312: 75-79.

Golden, T.A., Schauer, S.E., Lang, J.D., Pien, S., Mushegian, A.R., Grossniklaus, U., Meinke, D.W., and Ray, A. 2002. Short Integuments1/suspensor 1/carpel Factory, a Dicer homolog, is a maternal effect gene required for embryo development in Arabidopsis. Plant Physiol. 130: 808-822.

Grimanelli, D., Perotti, E., Ramirez, J., and Leblanc, O. 2005. Timing of the maternal-to-zygotic transition during early seed development in maize. Plant Cell 17: 1061-1072.

Grossniklaus, U. and Schneitz, K. 1998. The molecular and genetic basis of ovule and megagametophyte development. Semin. Cell Dev. Biol. 9: 227-238.

Gutiérrez-Marcos, J.F., Costa, L.M., Biderre-Petit, C., Khbaya, B., O'Sullivan, D.M., Wormald, M., Perez, P., and Dickinson, H.G. 2004. maternally expressed genel is a novel maize endosperm transfer cell-specific gene with a maternal parentof-origin pattern of expression. Plant Cell 16: 1288-1301.

Harper, J.L., Lovell, P.H., and Moore, K.G. 1970. The shapes and sizes of seeds. Annu. Rev. Ecol. Syst. 1: 327-356.

Harvey, E.B. 1936. Parthenogenetic merogony or cleavage without nuclei in Arbacia punctulata. Biol. Bull. 71: 101-121.

Ingouff, M., Hamamura, Y., Gourgues, M., Higashiyama, T., and Berger, F. 2007. Distinct dynamics of HISTONE3 variants between the two fertilization products in plants. Curr. Biol. 17: 1032-1037.

Jürgens G. 1992. Pattern formation in the flowering plant embryo. Curr. Opin. Genet. Dev. 2: 567-570.

Kane, D.A., Hammerschmidt, M., Mullins, M.C., Maischein, H.M., Brand, M., van Eeden, F.J., Furutani-Seiki, M., Granato, M., Haffter, P., Heisenberg, C.P., et al. 1996. The zebrafish epiboly mutants. Development 123: 47-55.

Leduc, N., Matthys-Rochon, E., Rougier, M., Mogensen, L., Holm, P., Magnard, J.L., and Dumas, C. 1996. Isolated maize zygotes mimic in vivo embryonic development and express microinjected genes when cultured in vitro. Dev. Biol. 177: 190-203.

Leroy, O., Hennig, L., Breuninger, H., Laux, T., and Kohler, C. 2007. Polycomb group proteins function in the female gametophyte to determine seed development in plants. Development 
134: 3639-3648.

Liang, H.L., Nien, C.Y., Liu, H.Y., Metzstein, M.M., Kirov, N., and Rushlow, C. 2008. The zinc-finger protein Zelda is a key activator of the early zygotic genome in Drosophila. Nature 456: 400-403.

Loppin, B., Berger, F., and Couble, P. 2001. The Drosophila maternal gene sesame is required for sperm chromatin remodeling at fertilization. Chromosoma 110: 430-440.

Lukowitz, W., Roeder, A., Parmenter, D., and Somerville, C. 2004. A MAPKK kinase gene regulates extra-embryonic cell fate in Arabidopsis. Cell 116: 109-119.

Mathavan, S., Lee, S.G., Mak, A., Miller, L.D., Murthy, K.R., Govindarajan, K.R., Tong, Y., Wu, Y.L., Lam, S.H., Yang, H., et al. 2005. Transcriptome analysis of zebrafish embryogenesis using microarrays. PLoS Genet. 1: 260-276.

Mayer, U., Büttner, G., and Jürgens, G. 1993. Apical-basal pattern formation in the Arabidopsis embryo: Studies on the role of the gnom gene. Development 117: 149-162.

Meyer, S. and Scholten, S. 2007. Equivalent parental contribution to early plant zygotic development. Curr. Biol. 17: 1686-1691.

Mishima, Y., Giraldez, A.J., Takeda, Y., Fujiwara, T., Sakamoto, H., Schier, A.F., and Inoue, K. 2006. Differential regulation of germline mRNAs in soma and germ cells by zebrafish miR430. Curr. Biol. 16: 2135-2142.

Moody, S.A., Bauer, D.V., Hainski, A.M., and Huang, S. 1996. Determination of Xenopus cell lineage by maternal factors and cell interactions. Curr. Top. Dev. Biol. 32: 103-138.

Moore, J.M. 2002. "Isolation and characterization of gametophytic mutants in Arabidopsis thaliana." Ph.D. thesis, State University of New York, Stony Brook.

Mtango, N.R., Potireddy, S., and Latham K.E. 2008. Oocyte quality and maternal control of development. Int. Rev. Cell Mol. Biol. 268: 223-290.

Newport, J. and Kirschner, M. 1982a. A major developmental transition in early Xenopus embryos. I. Characterization and timing of cellular changes at the midblastula stage. Cell 30: 675-686.

Newport, J. and Kirschner, M. 1982b. A major developmental transition in early Xenopus embryos. II. Control of the onset of transcription. Cell 30: 687-696.

Ning, J., Peng, X.B., Qu, L.H., Xin, H.P., Yan, T.T., and Sun, M. 2006. Differential gene expression in egg cells and zygotes suggests that the transcriptome is restructed before the first zygotic division in tobacco. FEBS Lett. 580: 1747-1752.

Okada, T., Endo, M., Singh, M.B., and Bhalla, P.L. 2005. Analysis of the histone $\mathrm{H} 3$ gene family in Arabidopsis and identification of the male-gamete-specific variant AtMGH3. Plant J. 44: 557-568.

Pagnussat, G.C., Yu, H.J., Ngo, Q.A., Rajani, S., Mayalagu, S., Johnson, C.S., Capron, A., Xie, L.F., Ye, D., and Sundaresan, V. 2005. Genetic and molecular identification of genes required for female gametophyte development and function in Arabidopsis. Development 132: 603-614.

Park, S. and Harada, J.J. 2008. Arabidopsis embryogenesis. Methods Mol. Biol. 427: 3-16.

Pelegri, F. 2003. Maternal factors in zebrafish development. Dev. Dyn. 228: 535-554.

Perrimon, N., Engstrom, L., and Mahowald, A.P. 1989. Zygotic lethals with specific maternal effect phenotypes in Drosophila melanogaster. I. Loci on the X chromosome. Genetics 121: 333-352.

Perrimon, N., Lanjuin, A., Arnold, C., and Noll, E. 1996. Zygotic lethal mutations with maternal effect phenotypes in Drosophila melanogaster. II. Loci on the second and third chromosomes identified by P-element-induced mutations. Genetics 144: 1681-1692.

Poccia, D., Wolff, R., Kragh, S., and Williamson, P. 1985. RNA synthesis in male pronuclei of the sea urchin. Biochim. Biophys. Acta 824: 349-356.

Pritchard, D.K. and Schubiger, G. 1996. Activation of transcription in Drosophila embryos is a gradual process mediated by the nucleocytoplasmic ratio. Genes Dev. 10: 1131-1142.

Reik, W. 2007. Stability and flexibility of epigenetic gene regulation in mammalian development. Nature 447: 425-432.
Robbins, L.G. 1980. Maternal-zygotic lethal interactions in Drosophila melanogaster: The effects of deficiencies in the zestewhite region of the $X$ chromosome. Genetics 96: 187-200.

Rojo, E., Gillmor, C.S., Kovaleva, V., Somerville, C.R., and Raikhel, N.V. 2001. VACUOLELESS1 is an essential gene required for vacuole formation and morphogenesis in Arabidopsis. Dev. Cell 1: 303-310.

Ronceret, A., Gadea-Vacas, J., Guilleminot, J., Lincker, F., Delorme, V., Lahmy, S., Pelletier, G., Chabouté, M.E., and Devic, M. 2008. The first zygotic division in Arabidopsis requires de novo transcription of thymidylate kinase. Plant $J$. 53: 776-789.

Ronshaugen, M. and Levine, M. 2004. Visualization of transhomolog enhancer-promoter interactions at the $A b d-B$ Hox locus in the Drosophila embryo. Dev. Cell 7: 925-932.

Ruzov, A., Dunican, D.S., Prokhortchouk, A., Pennings, S., Stancheva, I., Prokhortchouk, E., and Meehan, R.R. 2004. Kaiso is a genome-wide repressor of transcription that is essential for amphibian development. Development 131: 6185-6194.

Santos, F., Hendrich, B., Reik, W., and Dean, W. 2002. Dynamic reprogramming of DNA methylation in the early mouse embryo. Dev. Biol. 241: 172-182.

Sarmento, O.F., Digilio, L.C., Wang, Y., Perlin, J., Herr, J.C., Allis, C.D. and Coonrod, S.A. 2004. Dynamic alterations of specific histone modifications during early murine development. J. Cell Sci. 117: 4449-4459.

Schauer, I.E. and Wood, W.B. 1990. Early C. elegans embryos are transcriptionally active. Development 110: 1303-1317.

Scholten, S., Lörz, H., and Kranz, E. 2002. Paternal mRNA and protein synthesis coincides with male chromatin decondensation in maize zygotes. Plant J. 32: 221-231.

Schultz, R.M. 2002. The molecular foundations of the maternal to zygotic transition in the preimplantation embryo. Hum. Reprod. Update 8: 323-331.

Semotok, J.L., Luo, H., Cooperstock, R.L., Karaiskakis, A., Vari, H.K., Smibert, C.A., and Lipshitz, H.D. 2008. Drosophila maternal Hsp 83 mRNA destabilization is directed by multiple SMAUG recognition elements in the open reading frame. Mol. Cell. Biol. 28: 6757-6772.

Seydoux, G. and Fire, A. 1994. Soma-germline asymmetry in the distributions of embryonic RNAs in Caenorhabditis elegans. Development 120: 2823-2834.

Shaw, G. and Kamen, R. 1986. A conserved AU sequence from the $3^{\prime}$ untranslated region of GM-CSF mRNA mediates selective mRNA degradation. Cell 46: 659-667.

Sørensen, M.B., Chaudhury, A.M., Robert, H., Bancharel, E., and Berger, F. 2001. Polycomb group genes control pattern formation in plant seed. Curr. Biol. 11: 277-281.

Springer, P.S., McCombie, W.R., Sundaresan, V., and Martienssen, R.A. 1995. Gene trap tagging of PROLIFERA, an essential MCM2-3-5-like gene in Arabidopsis. Science 268: 877-880.

Springer, P.S., Holding, D.R., Groover, A., Yordan, C., and Martienssen, R.A. 2000. The essential Mcm7 protein PROLIFERA is localized to the nucleus of dividing cells during the $\mathrm{G}_{1}$ phase and is required maternally for early Arabidopsis development. Development 127: 1815-1822.

Sprunck, S., Baumann, U., Edwards, K., Langridge, P., and Dresselhaus, T. 2005. The transcript composition of egg cells changes significantly following fertilization in wheat (Triticum aestivum L.). Plant J. 41: 660-672.

Stancheva, I. and Meehan, R.R. 2000. Transient depletion of $\mathrm{xDnmt} 1$ leads to premature gene activation in Xenopus embryos. Genes Dev. 14: 313-327.

Stancheva, I., El-Maarri, O., Walter, J., Niveleau, A., and Meehan, R.R. 2002. DNA methylation at promoter regions regulates the timing of gene activation in Xenopus laevis embryos. Dev. Biol. 243: $155-165$.

Stitzel, M.L. and Seydoux, G. 2007. Regulation of the oocyte-tozygote transition. Science 316: 407-408.

Stroband, H.W.J., te Krounie, G., and van Gestel, W. 1992. Differential susceptibility of early steps in carp (Cyrinus carpio) development to $\alpha$-amanitin. Dev. Genes Evol. 202: 61-65.

Tadros, W., Westwood, J.T., and Lipshitz, H.D. 2007a. The mother-to-child transition. Dev. Cell 12: 847-849. 
Tadros, W., Houston, S.A., Bashirullah, A., Cooperstock, R.L., Semotok, J.L., Reed, B.H., and Lipshitz, H.D. 2003. Regulation of maternal transcript destabilization during egg activation in Drosophila. Genetics 164: 989-1001.

Tadros, W., Goldman, A.L., Babak, T., Menzies, F., Vardy, L., Orr-Weaver, T., Hughes, T.R., Westwood, J.T., Smibert, C.A., and Lipshitz, H.D. 2007b. SMAUG is a major regulator of maternal mRNA destabilization in Drosophila and its translation is activated by the PAN GU kinase. Dev. Cell 12: 143-155.

Telford, N.A., Watson, A.J., and Schultz, G.A. 1990. Transition from maternal to embryonic control in early mammalian development: A comparison of several species. Mol. Reprod. Dev. 26: $90-100$

ten Bosch, J.R., Benavides, J.A., and Cline, T.W. 2006. The TAGteam DNA motif controls the timing of Drosophila preblastoderm transcription. Development 133: 1967-1977.

Tzafrir, I., Pena-Muralla, R., Dickerman, A., Berg, M., Rogers, R., Hutchens, S., Sweeney, T.C., McElver, J., Aux, G., Patton, D., and Meinke, D. 2004. Identification of genes required for embryo development in Arabidopsis. Plant Physiol. 135: 1206-1220.

Vaillant, I. and Paszkowski, J. 2007. Role of histone and DNA methylation in gene regulation. Curr. Opin. Plant Biol. 10: 528-533.

Vielle-Calzada, J.P., Baskar, R., and Grossniklaus, U. 2000. Delayed activation of the paternal genome during seed development. Nature 404: 91-94.

Vielle-Calzada, J.P., Thomas, J., Spillane, C.S., Coluccio, A.,
Hoeppner, M.A., and Grossniklaus, U. 2000. Maintenance of genomic imprinting at Arabidopsis MEDEA locus requires zygotic DDMI activity. Genes Dev. 13: 2971-2982.

Weijers, D., Geldner, N., Offringa, R., and Jürgens, G. 2001. Seed development: Early paternal gene activity in Arabidopsis. Nature 414: 709-710.

Wharton, R.P., Sonoda, J., Lee, T., Patterson, M., and Murata, Y. 1998. The Pumilio RNA-binding domain is also a translational regulator. Mol. Cell 1: 863-872.

Wu, X., Chory, J., and Weigel, D. 2007. Combinations of WOX activities regulate tissue proliferation during Arabidopsis embryonic development. Dev. Biol. 309: 306-316.

Yadegari, R., Kinoshita, T., Lotan, O., Cohen, G., Katz, A., Choi, Y., Nakashima, K., Harada, J.J., Goldberg, R.B., Fischer, R.L., and Ohad, N. 2000. Mutations in the FIE and MEA genes that encode interacting polycomb proteins cause parent-of-origin effects on seed development by distinct mechanisms. Plant Cell 12: 2367-2382.

Yang, J., Tan, C., Darken, R.S., Wilson, P.A., and Klein, P.S. 2002. $\beta$-Catenin/Tcf-regulated transcription prior to the midblastula transition. Development 129: 5743-5752.

Zalokar, M. 1976. Autoradiographic study of protein and RNA formation during early development of Drosophila eggs. Dev. Biol. 49: 425-437.

Zeng, F., Baldwin, D.A., and Schultz, R.M. 2004. Transcript profiling during preimplantation mouse development. Dev. Biol. 272: 483-496. 


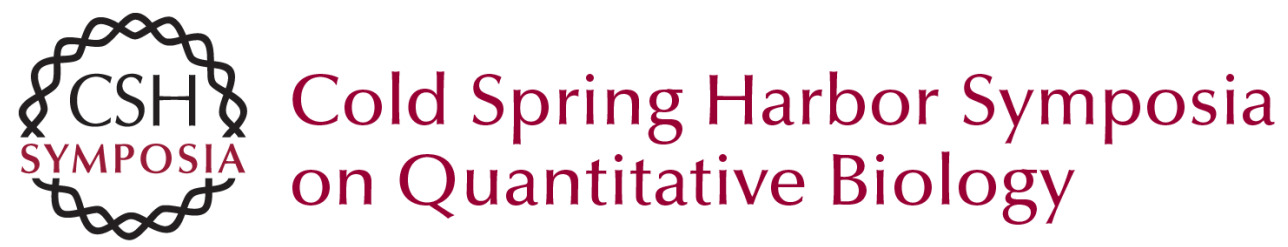

\title{
The Maternal to Zygotic Transition in Animals and Plants
}

\author{
C. Baroux, D. Autran, C.S. Gillmor, et al.
}

Cold Spring Harb Symp Quant Biol 2008 73: 89-100 originally published online February 9, 2009 Access the most recent version at doi:10.1101/sqb.2008.73.053

References This article cites 100 articles, 38 of which can be accessed free at: http://symposium.cshlp.org/content/73/89.full.html\#ref-list-1

License

Email Alerting Receive free email alerts when new articles cite this article - sign up in the box at the Service top right corner of the article or click here.

To subscribe to Cold Spring Harbor Symposia on Quantitative Biology go to:

http://symposium.cshlp.org/subscriptions 